\title{
Norfloxacin-Toxicity for Zebrafish (Danio rerio) Focused on Oxidative Stress Parameters
}

\author{
Marta Bartoskova, Radka Dobsikova, Vlasta Stancova, Ondrej Pana, Dana Zivna, \\ Lucie Plhalova, Jana Blahova, and Petr Marsalek
}

Department of Veterinary Public Health and Animal Welfare, Faculty of Veterinary Hygiene and Ecology, University of Veterinary and Pharmaceutical Sciences Brno, Palackého tř́da 1/3, 61242 Brno, Czech Republic

Correspondence should be addressed to Marta Bartoskova; h11020@vfu.cz

Received 19 December 2013; Revised 10 February 2014; Accepted 10 February 2014; Published 13 March 2014

Academic Editor: Josef Velíšek

\begin{abstract}
Copyright (C) 2014 Marta Bartoskova et al. This is an open access article distributed under the Creative Commons Attribution License, which permits unrestricted use, distribution, and reproduction in any medium, provided the original work is properly cited.

The aim of the study was to investigate the effects of subchronic exposure of zebrafish (Danio rerio) to a fluoroquinolone norfloxacin, using selected oxidative stress parameters as a target. Toxicity tests were performed on zebrafish according to the OECD Guidelines number 203 and number 215. In the Subchronic Toxicity Test, a significant $(P<0.01)$ increase in the activity of glutathione peroxidase, glutathione S-transferase, and catalase was found. In the test, norfloxacin did not affect lipid peroxidation and catalytic activity of glutathione reductase. From the results, we can conclude that norfloxacin has a negative impact on specific biochemical processes connected with the production of reactive oxygen species in fish tested.
\end{abstract}

\section{Introduction}

Fluoroquinolone antibacterial agents are widely used for the treatment of various infections, especially against gramnegative bacteria [1]. Although this type of use leads to an entry of these compounds into the environment through the excretion of unmetabolised quinolones and the disposal of unused drugs, the main source of aquatic compartments pollution with these drugs is their use in aquaculture [2].

Fluoroquinolones are among the antimicrobial chemotherapeutics frequently detected in the aquatic environment in relatively high concentrations ranging from ng $\mathrm{L}^{-1}$ to $\mu \mathrm{g} \mathrm{L}^{-1}$. Their ubiquitous presence has been reported, for example, in waste water treatment plant influents [3], as well as groundwater [4], surface waters [5], and even in drinking water [6].

These drugs are rather resistant to microbial degradation [7] and may persist in water bodies because of their strong sorption properties. Photodegradation is expected to play an important role in fluoroquinolone fate in some sunlit surface waters [8]. Also chemical oxidation may be significant for their degradation [9].

Norfloxacin is a synthetic chemotherapeutic agent usually used to treat urinary tract infections $[10,11]$. Norfloxacin belongs to the third generation of quinolones. The mechanism of norfloxacin action is the inhibition of DNA gyrase (a type II topoisomerase), which is an essential bacterial enzyme [12]. NOEC (no observed effect concentration) for norfloxacin was determined to be $10.38 \mu \mathrm{g} \mathrm{L}^{-1}$ by long-term bioluminescence inhibition assay with $V$. fischeri [2]. The $\mathrm{EC}_{50}$ and NOEC of this compound for Chlorella vulgaris are 10.4 and $4.1 \mathrm{mg} \mathrm{L}^{-1}$, respectively [13].

The aim of this study was to investigate the subchronic effect of norfloxacin on zebrafish (Danio rerio). For the determination of norfloxacin effects, selected oxidative stress parameters such as glutathione peroxidase, glutathione reductase, glutathione S-transferase, catalase, and lipid peroxidation were used as a target.

\section{Materials and Methods}

In the study, two tests of norfloxacin were performed. As the model organism, zebrafish (Danio rerio) was used. The first test was performed according to the OECD Guideline number 203 (Fish, Acute Toxicity Test) [14] and the second one was performed according to the OECD Guideline number 215 (Fish, Juvenile Growth Test) [15]. 
2.1. Acute Toxicity Test. Acute Toxicity Test was performed according to OECD number 203. Norfloxacin of $\geq 98.0 \%$ chemical purity (Sigma-Aldrich, Czech Republic) was dissolved in water with the addition of solvent, dimethyl sulfoxide (DMSO). The final concentration of DMSO was $0.1 \%$ in each test aquarium. For the test, we used five ascending concentrations of norfloxacin $\left(0.05,1,5,10\right.$, and $\left.30 \mathrm{mg} \mathrm{L}^{-1}\right)$, all in a duplicate and two control groups (only water and water with a solvent). After 7 days of acclimatization, ten juvenile fish (aged 30 days) were placed in each 4 liter glass aquarium. A total of 120 zebrafish were used in the test. Food had been withheld 72 hours before the test; during the test fish were not fed. The test was performed using a semistatic method with the solutions renewed every 24 hours. Fish conditions and a number of dead fish were checked every 24 hours. Duration of the test was 96 hours. Water temperature, $\mathrm{pH}$, and oxygen saturation were monitored every 24 hours and were as follows: temperature $23 \pm 0.5^{\circ} \mathrm{C}$, oxygen concentrations above $60 \%$ (ranged from $85 \%$ to $96 \%$ ), and $\mathrm{pH}$ ranged from 8.28 to 8.61 .

Water samples were collected for the measurement of the real concentration of norfloxacin in water every 48 hours. The concentrations of the test substance were measured using HPLC with photometric detection. Norfloxacin concentration did not fall under $90 \%$ of the nominal value.

The aim of the acute toxicity test was to determine the range of concentrations for a subsequent Subchronic Toxicity Test.

2.2. Subchronic Toxicity Test. Subchronic Toxicity Test of norfloxacin was performed according to OECD Guideline number 215. In the test, juvenile (30 days old) zebrafish (Danio rerio) were used. Fish had been acclimatized for 14 days before the test started.

Norfloxacin was dissolved in water using DMSO in volume of $2 \mu \mathrm{LL}^{-1}$ as a solvent. Fish were exposed to five ascendant sublethal concentrations, that is, 0.0001 (an environmental concentration), $0.1,1,10$, and $30 \mathrm{mg} \mathrm{L}^{-1}$ (all in a duplicate). In the test, two control groups (the first one with only water, the second one with water and solvent, DMSO) were used. Fish were randomly distributed into 30 liter glass aquaria, 50 specimens in each aquarium. A total of 600 fish were used in the test.

The experiment was conducted in a flow-through system with a test solution renewal every twelve hours. During the test, water condition parameters were monitored at 24-hour intervals. Water quality values were measured as follows: temperature $23.7-24.6^{\circ} \mathrm{C}$, oxygen saturation above $60 \%$ (ranged between $80 \%$ and 94\%), and $\mathrm{pH} 8.19-8.60$. In the course of the test, fish were fed with dried Artemia salina without shells at $8 \%$ of body weight per day. The food ration was based on an initial fish weight and recalculated after 14 days of the test. Duration of the test was 28 days.

Water samples were collected every 7 th day to measure real concentrations of norfloxacin in water. Analyzed concentrations of norfloxacin in water were found to be above $92 \%$ of the nominal concentrations in the course of subchronic test, which is in accordance with the test validation criteria.
At the end of the test, fish were euthanased and then weighed. Their tank-average specific growth rates were determined. Tank-average specific growth rates were calculated using the following formula according to OECD method number 215:

$$
r=\frac{\overline{\log _{e} W_{2}}-\overline{\log _{e} W_{1}}}{t_{2}-t_{1}} * 100,
$$

where $r$ is the tank-average-specific growth rate; $W_{1}, W_{2}$ are the weights of a particular fish at times $t_{1}$ and $t_{2}$, respectively; $\overline{\log _{e} W_{1}}$ is the average of the logarithms of the values $W_{1}$ for the fish in the tank at the start of the study period; $\overline{\log _{e} W_{2}}$ is the average of the logarithms of the values $W_{2}$ for the fish in the tank at the end of the study period; $t_{1}, t_{2}$ is the time (days) at the start and end of the study period.

2.3. Fish Sampling and Homogenization. At the end of the Subchronic Toxicity Test, fish were euthanased by approved anesthetic (MS222). Body weight and length of each fish were recorded. Fish were frozen and stored at $-85^{\circ} \mathrm{C}$ until homogenization. Whole body samples were weighed and homogenized $(1: 10 \mathrm{w} / \mathrm{v})$ using a phosphate buffer $(\mathrm{pH} 7.2)$. The homogenate was then divided into two parts. The first one was used for the measurement of thiobarbituric acid reactive substances (TBARS), the second was centrifuged $(10,500 \mathrm{~g}$ at $4^{\circ} \mathrm{C}$ for $20 \mathrm{~min}$ ), and the obtained supernatant fraction was then used for the determination of catalytic activities glutathione peroxidase (GPx), glutathione reductase (GR), glutathione S-transferase(GST), and catalase (CAT).

2.4. Measurement of Oxidative Stress Parameters. To determine a lipid peroxidation in fish samples, the TBARS (thiobarbituric acid reactive substances) method described by Lushchak et al. (2005) was used. TBARS were measured at $535 \mathrm{~nm}$ and the concentration was expressed in nmol of TBARS per gram of tissue wet weight [16].

The catalytic activity of glutathione peroxidase and glutathione reductase was determined spectrophotometrically at $340 \mathrm{~nm}$ by catalysis conversion of oxidized glutathione (GSSG) to reduced glutathione (GSH) for the consumption of NADPH. The specific activities were expressed as the nmol of NADPH consumption per min per mg of protein [17].

Total catalytic activity of glutathione S-transferase was determined by the measurement of the conjugation of 1chloro-2,4-dinitrobenzene with reduced glutathione (GSH) at $340 \mathrm{~nm}$ [18]. The specific activity was expressed in the units of nmol of formed product per min per mg of protein.

For the assessment of GST and GR catalytic activities, the concentration of proteins was determined by Bicinchoninic Acid Protein Assay Kit (Sigma-Aldrich, St. Louis, MO), in which bovine serum albumin was used as a standard [19].

The catalytic activity of catalase was determined by a spectrophotometrical measurement of $\mathrm{H}_{2} \mathrm{O}_{2}$ breakdown at $240 \mathrm{~nm}$. The specific activity of the enzyme was expressed as $\mu$ mol of decomposed $\mathrm{H}_{2} \mathrm{O}_{2}$ per min per mg of protein [20].

All spectrophotometric measurements were performed using the Varioskan Flash Spectral Scanning Multimode Reader (Thermo Fisher Scientific Inc., USA). 
2.5. Determination of Norfloxacin Concentration in Water. Measurement of norfloxacin was based on high-performance liquid chromatography coupled with triple quadrupole tandem mass spectrometry (LC-ESI-MS/MS). Samples were filtered and used for LC-ESI-MS/MS analysis. A Thermo Scientific UHPLC Accela 1250 system was connected to a Thermo Scientific TSQ Quantum Access MAX Triple Quadrupole Instrument (Thermo, San Jose, CA, USA) equipped with heated electrospray ionization (HESI-II) probe. A Thermo Scientific Hypersil $\mathrm{C}_{18}(2.1 \mathrm{~mm} \times 50 \mathrm{~mm}, 1.9 \mu \mathrm{m})$ column was used at a constant flow rate of $300 \mu \mathrm{L} \mathrm{min}^{-1}$. Mobile phase consisted of water containing $0.1 \%$ formic acid (v/v) (solvent A) and acetonitrile containing $0.1 \%$ formic acid (solvent B). The full loop injection volume of the tissue extract was set at $20 \mu \mathrm{L}$. The heated electrospray ionization was operated in the positive-ion mode under specific conditions: standard of norfloxacin was purchased from Sigma-Aldrich (St. Louis, $\mathrm{MO}$ ). All solvents were residual analysis purity (Chromservis, Ltd., CZ). Coefficient of variation for between-series was 3.1\%. The limit of detection was $91 \mathrm{ng} \mathrm{L}^{-1}$.

2.6. Statistical Analysis. Oxidative stress biomarkers were tested for a normal distribution using the Shapiro-Wilk test. After testing for homogeneity of variance across groups, an analysis of variance (one-way ANOVA) was used. The differences among test groups were assessed with the Tukey-HSD test with $P<0.05$ as the level of significance.

2.7. Ethical Statement. All experimental procedures were approved by the institutional committee and performed in a compliance with institutional guidelines and national legislation (Act number 246/1992 Coll., on the Protection of Animals Against Cruelty, as amended).

\section{Results}

No significant difference was found between the results of control group with only water and the control one with water and the addition of a solvent (DMSO). Therefore, we used only one average value for the control group.

3.1. Mortality of Fish in Subchronic Test. Mortality of juvenile fish was found to be less than $8 \%$ in all experiment groups. In the control group, mortality did not exceed $4 \%$, which is in an agreement with the validation criteria of the juvenile growth test.

3.2. Growth Rate. At the end of the Subchronic Toxicity Test, all fish were weighed and their length was measured. Statisti$\mathrm{cal}$ analysis of the somatic parameter was then performed.

The specific growth rate $r$ was calculated for all tested concentrations and control. No significant differences were found among the groups tested (Figure 1).

3.3. Effect of Norfloxacin on Biotransformation and Antioxidant Enzymes. An increase in glutathione peroxidase (GPx) activity was found in fish exposed to all concentrations of

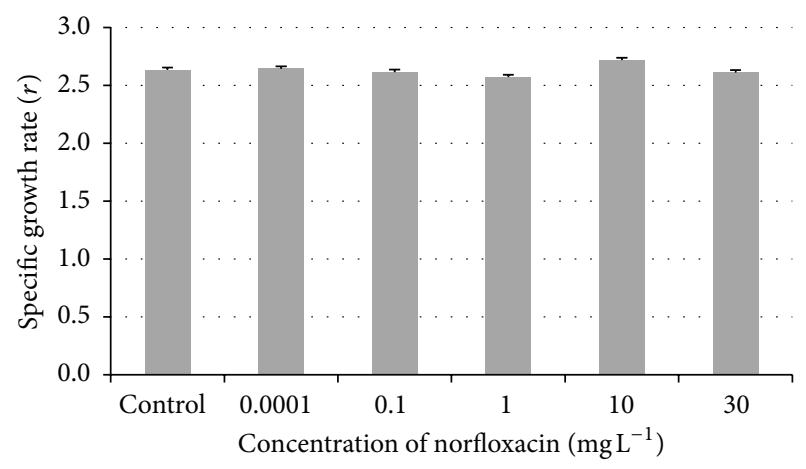

FIGURE 1: Zebrafish specific growth rate $(r)$ in subchronic toxicity test (values in mean \pm SEM); SEM = standard error of mean.

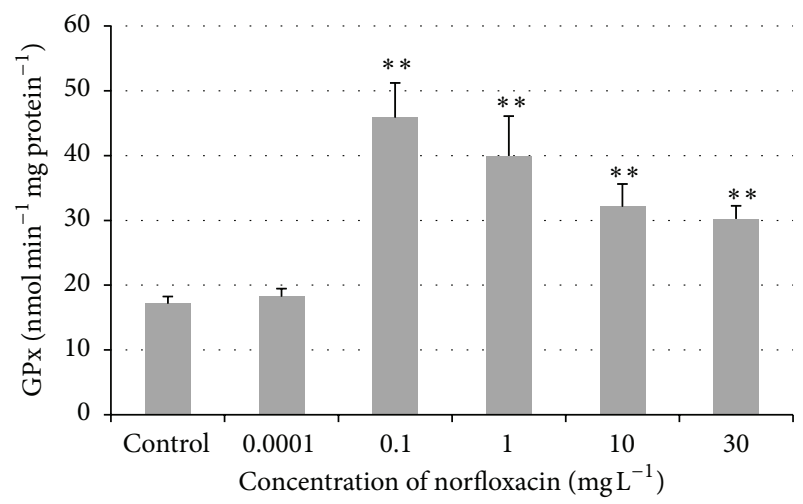

Figure 2: Glutathione peroxidase (GPx) activity in zebrafish exposed to norfloxacin (values in mean \pm SEM); SEM = standard error of mean; $* *=$ a significant increase in GPx activity $(P<0.01)$.

norfloxacin $\left(0.0001,0.1,1,10\right.$, and $\left.30 \mathrm{mg} \mathrm{L}^{-1}\right)$ compared to the control group (Figure 2). But only in the groups exposed to norfloxacin concentrations of $0.1,1,10$, and $30 \mathrm{mg} \mathrm{L}^{-1}$ $\left(45.86,39.92,32.13\right.$, and $30.24 \mathrm{nmol} \mathrm{min}^{-1} \mathrm{mg}$ protein $\left.^{-1}\right) \mathrm{GPx}$ activity was significantly higher $(P<0.01)$ compared to the control group (17.16 nmol min ${ }^{-1} \mathrm{mg}$ protein $\left.{ }^{-1}\right)$. The increase in the activity of glutathione reductase (GR) was found in norfloxacin concentrations of $0.0001,0.1,1$, and $30 \mathrm{mg} \mathrm{L}^{-1}$ $\left(11.33,12.96,13.41\right.$, and $12.18 \mathrm{nmol} \mathrm{min}^{-1} \mathrm{mg}$ protein $\left.^{-1}\right)$ compared to the control group (10.59 $\mathrm{nmol} \mathrm{min}^{-1} \mathrm{mg}$ protein $\left.^{-1}\right)$, but the increase did not reach significance (Figure 3 ).

The activity of glutathione S-transferase (GST) increased in all tested groups exposed to 0.0001, 0.1, 1,10 , and $30 \mathrm{mg} \mathrm{L}^{-1}(163.16,137.49,147.64,152.06$, and $145.03 \mathrm{nmol} \mathrm{min}^{-1} \mathrm{mg}$ protein ${ }^{-1}$ ) of norfloxacin compared to the control group $\left(131.86 \mathrm{nmol} \mathrm{min}^{-1} \mathrm{mg}_{\text {protein }}{ }^{-1}\right)$. The highest and significantly different $(P<0.01)$ value of GST activity was found in the environmental concentration $0.0001 \mathrm{mg} \mathrm{L}^{-1}$ compared to the control group (Figure 4).

A significant $(P<0.01)$ increase in catalase (CAT) activity was found in all tested concentrations compared to the control group (Figure 5). In the concentrations of $0.0001,0.1,1,10$, and $30 \mathrm{mg} \mathrm{L}^{-1}$, catalase activity was found to be $128.29,128.37,149.35,127.53$, and $145.96 \mu \mathrm{mol} \mathrm{min}^{-1} \mathrm{mg}$ 


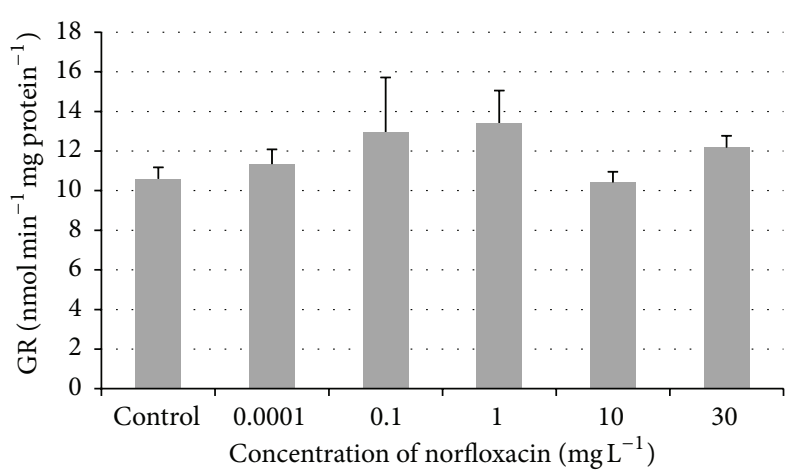

FIGURE 3: Glutathione reductase (GR) activity in zebrafish exposed to norfloxacin (values in mean \pm SEM); SEM = standard error of mean.

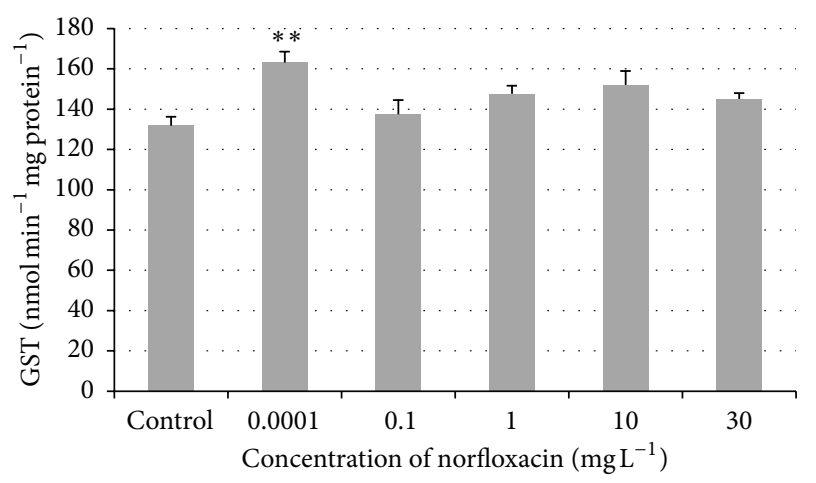

FIGURE 4: Glutathione S-transferase (GST) activity in zebrafish exposed to norfloxacin (values in mean \pm SEM); SEM $=$ standard error of mean; $* *=$ a significant increase in GST activity $(P<0.01)$.

protein $^{-1}$. In the control group, its activity was found to be $107.36 \mu \mathrm{mol} \mathrm{min}^{-1} \mathrm{mg}$ protein ${ }^{-1}$.

3.4. Effect of Norfloxacin on Lipid Peroxidation (TBARS). No significant difference was found in all tested concentrations $-0.0001,0.1,1,10$, and $30 \mathrm{mg} \mathrm{L}^{-1}(32.22,26.56,28.01,35.86$, and $22.54 \mathrm{nmol} \mathrm{g}^{-1}$ of wet weight) of norfloxacin when compared to the control group ( $21.63 \mathrm{nmol} \mathrm{g}^{-1}$ of wet weight). In our study, norfloxacin did not affect the lipid peroxidation (Figure 6).

\section{Discussion}

In the literature, there is little information on the effect of norfloxacin (or other fluoroquinolones) on fish and other water organisms; therefore, we had to compare our results with the effect of other pharmaceuticals on fish.

In our study, we did not find any significant differences in growth rates in zebrafish exposed to all norfloxacin concentrations when compared to the control group. These results disagree with the findings of Nie et al.s study [21], in which the effect of norfloxacin on the freshwater microalga (Scenedesmus obliquus) was evaluated. Nie et al. proved

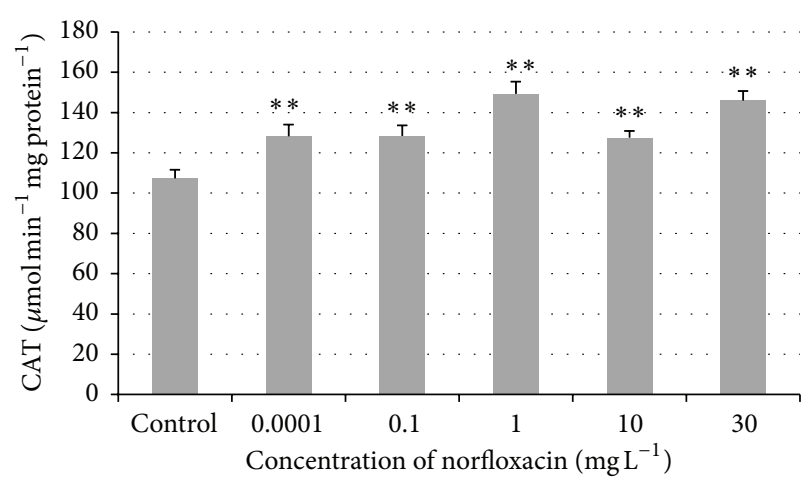

FIGURE 5: Catalase (CAT) activity in zebrafish exposed to norfloxacin (values in mean \pm SEM); SEM $=$ standard error of mean; $* *=$ a significant increase in CAT activity $(P<0.01)$.

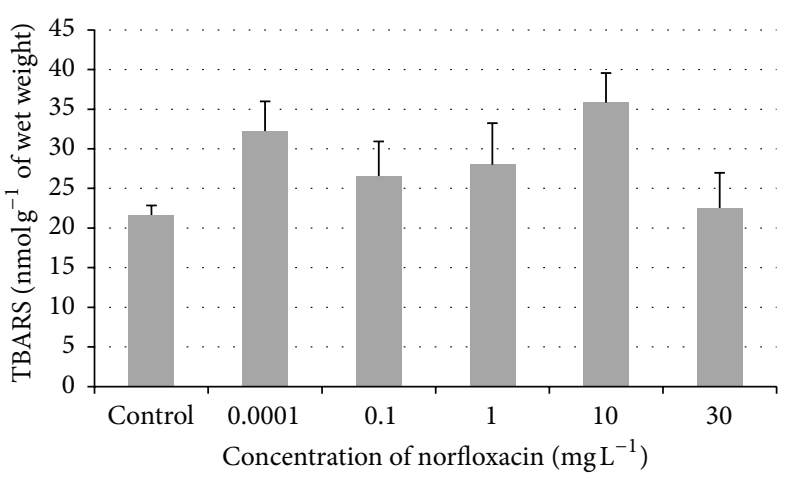

FIGURE 6: TBARS concentrations in zebrafish in Subchronic Toxicity Test (values in mean \pm SEM); SEM = standard error of mean.

that the concentrations used in the test $\left(0.0-60.0 \mathrm{mg} \mathrm{L}^{-1}\right)$ inhibited growth rates of tested alga, which can be probably explained as a direct toxic effect of norfloxacin, an antimicrobial agent, to unicellular alga. The results of his study demonstrated that the concentration resulting in 50\% inhibition of algal growth rate after 48 hours of exposition $\left(48 \mathrm{~h} \mathrm{IC}_{50}\right.$ ) was found to be $38.49 \mathrm{mg} \mathrm{L}^{-1}$ [21]. In the study on the subchronic effect of diclofenac (a nonsteroidal antiinflammatory drug, NSAID) on early stages of common carp (Cyprinus carpio), no effect on body weight and growth was found in experimental fish compared to control [22]. This result is in an agreement with our results. In the study of Zivna et al. [23], toxic effect of acetylsalicylic acid (NSAID) in the concentration range from 0.004 to $250 \mathrm{mg} \mathrm{L}^{-1}$ on zebrafish was tested and the increase in body weight and specific growth rate was found in all experimental groups compared to the control group.

Glutathione peroxidase (GPx) is an enzyme which transforms hydroperoxides to hydroxyl compounds using a reduced glutathione as a substrate. In our study, a significant increase $(P<0.01)$ was found in the activity of glutathione peroxidase in zebrafish exposed to norfloxacin at the concentrations of $0.1,1,10$, and $30 \mathrm{mg} \mathrm{L}^{-1}$. It can be explained by the presence of oxidative substances in cells, which may 
cause an increase in antioxidant enzymes activities as a defense mechanism [24]. Environmental concentration of norfloxacin $\left(0.0001 \mathrm{mg} \mathrm{L}^{-1}\right)$ did not cause an increase in the activity of GPx in our experiment. The increase in GPx activity was also found in the study performed on zebrafish exposed to ibuprofen (NSAIDs) in the concentrations of 0.05 , 1,8 , and $25 \mathrm{mg} \mathrm{L}^{-1}$ [25].

Glutathione reductase (GR) is an enzyme catalyzing the conversion of glutathione disulfide to reduced glutathione. The main function of reduced glutathione is the protection of cells from chemical insult [26,27]. In our study, we did not find significant differences in glutathione reductase activity in all concentrations tested. On the contrary, in the study of Zivna et al. [23], the exposure of zebrafish to acetylsalicylic acid in the concentrations of $0.004,0.4,40,120$, and $250 \mathrm{mg} \mathrm{L}^{-1}$ caused a significant increase in the activity of GR when compared to the control group.

The main function of glutathione S-transferase (GST) in the endogenous metabolism is the detoxification of xenobiotics and products of oxidative stress. GST provides cellular protection against toxic effects of a variety of environmental and endogenous chemicals [27]. The exposure of zebrafish to norfloxacin caused a nonsignificant increase in GST activity in all tested groups compared to the control group. A significant $(P<0.01)$ increase was found only in the fish exposed to environmental concentration $\left(0.0001 \mathrm{mg} \mathrm{L}^{-1}\right)$. In freshwater microalga (Scenedesmus obliquus) exposed to norfloxacin in the concentration range between 0.0 and $60 \mathrm{mg} \mathrm{L}^{-1}$, GST activity was found to be significantly increased at higher norfloxacin concentrations, reaching a peak value at $15 \mathrm{mg} \mathrm{L}^{-1}$ [21]. Oliveira et al. [28] investigated the effect of two antibiotics (oxytetracycline and amoxicillin) on zebrafish enzymes. GST activity was induced in muscle and gill samples. On the contrary, in head samples an inhibition trend was observed. In zebrafish exposed to oxytetracycline, GST activities were increased at almost all concentrations above $1 \mathrm{mg} \mathrm{L}^{-1}$ in muscle and liver samples. GST activity in zebrafish exposed to 40,120 , and $250 \mathrm{mg} \mathrm{L}^{-1}$ of acetylsalicylic acid in the study of Zivna et al. [23] was also found to be significantly higher. Stepanova et al. [22] studied the effects of diclofenac on early stages of common carp and found a significant increase in the GST activity at the highest tested concentration of diclofenac $\left(3 \mathrm{mg} \mathrm{L}^{-1}\right)$.

Catalase is an enzyme that catalyzes the conversion of a potentially oxidative molecule, $\mathrm{H}_{2} \mathrm{O}_{2}$ into $\mathrm{H}_{2} \mathrm{O}$ and $\mathrm{O}_{2}$ [29]. In our study, significantly higher catalase activity was found in all tested concentrations (0.0001, 0.1, 1, 10, and $30 \mathrm{mg} \mathrm{L}^{-1}$ ) compared to control. In the study of Wang et al., the toxicity of fluoroquinolone enrofloxacin associated with environmental stress in Tra catfish (Pangasianodon hypophthalmus) was tested. Fish were fed with pellets containing $1 \mathrm{~g} \mathrm{~kg}^{-1}$ enrofloxacin for 7 days. A 1.7 times increase in CAT activity in gills of the fish exposed to enrofloxacin was found in a low-density group ( 40 fish $\mathrm{m}^{-3}$ ) contrary to one and three days after the end of exposure (day 8 and 10); CAT activity was significantly lower than in the control group [29]. In the study of Oliveira et al., amoxicillin at the highest concentration $\left(221 \mathrm{mg} \mathrm{L}^{-1}\right)$ inhibited the activity of CAT in gills and head samples of zebrafish. Zebrafish exposed to oxytetracycline in the concentration of $25.0-100.0 \mathrm{mg} \mathrm{L}^{-1}$ exhibited a dose-dependent inhibition of CAT activity in head samples, whereas no alteration was observed in the other tissues analyzed [28].

The level of TBARS is used to measure the extent of lipid peroxidation. One of the major terminal products of lipid peroxidation is malondialdehyde [30,31]. Lipid peroxidation has been a major contributor to the loss of cell function under oxidative stress [32]. In our study, we did not find any significant effect of norfloxacin on lipid peroxidation. In the study of Wang et al., in which the effect of enrofloxacin on Tra catfish (Pangasianodon hypophthalmus) in the relation to density stress was tested, lipid peroxidation in gills of enrofloxacin-fish reared at low (40 fish $\mathrm{m}^{-3}$ ) or high (120 fish $\mathrm{m}^{-3}$ ) density was significantly (more than 5-fold) higher than their respective control at day 7. On the contrary, lipid peroxidation in gills of enrofloxacin-fish reared at medium density (80 fish $\mathrm{m}^{-3}$ ) was significantly, 3-fold lower than in the control fish [29]. Juvenile rainbow trout (Oncorhynchus mykiss) exposed to six ascending concentrations $(5,10,15,20$, 25 , and $30 \mathrm{mg} \mathrm{L}^{-1}$ ) of carbamazepine (anticonvulsant drug) for $96 \mathrm{hrs}$ showed an increase in lipid peroxidation $(P<0.05)$ in gill and brain when compared to the control group [33].

\section{Conclusions}

The results of our study indicate that norfloxacin does not affect the growth rate in zebrafish. Norfloxacin in the tested concentrations affects some biomarkers of oxidative stress (GPx, GST, and CAT). The subchronic exposure of zebrafish to norfloxacin causes the increase in the activities of some antioxidant and biotransformation enzymes. Based on these results, we can conclude that norfloxacin (even in environmental concentrations) may have a negative impact on some biochemical processes connected with the production of ROS (reactive oxygen species) in aquatic organisms.

\section{Conflict of Interests}

The authors declare that there is no conflict of interests regarding the publication of this paper.

\section{Acknowledgments}

This research was supported by IGA VFU 19/2013/FVHE. The authors would like to thank Mrs. Veronika Simova for paper improvement and English correction.

\section{References}

[1] R. C. Owens Jr. and P. G. Ambrose, "Antimicrobial safety: focus on fluoroquinolones," Clinical Infectious Diseases, vol. 41, no. 2, pp. S144-S157, 2005.

[2] T. Backhaus, M. Scholze, and L. H. Grimme, "The single substance and mixture toxicity of quinolones to the bioluminescent bacterium Vibrio fischeri," Aquatic Toxicology, vol. 49, no. 1-2, pp. 49-61, 2000. 
[3] N. Vieno, T. Tuhkanen, and L. Kronberg, "Elimination of pharmaceuticals in sewage treatment plants in Finland," Water Research, vol. 41, no. 5, pp. 1001-1012, 2007.

[4] R. Andreozzi, M. Raffaele, and P. Nicklas, "Pharmaceuticals in STP effluents and their solar photodegradation in aquatic environment," Chemosphere, vol. 50, no. 10, pp. 1319-1330, 2003.

[5] D. W. Kolpin, E. T. Furlong, M. T. Meyer et al., "Pharmaceuticals, hormones, and other organic wastewater contaminants in U.S. streams, 1999-2000: a national reconnaissance," Environmental Science and Technology, vol. 36, no. 6, pp. 1202-1211, 2002.

[6] K. K. Barnes, D. W. Kolpin, E. T. Furlong, S. D. Zaugg, M. T. Meyer, and L. B. Barber, "A national reconnaissance of pharmaceuticals and other organic wastewater contaminants in the United States-I). Groundwater," Science of the Total Environment, vol. 402, no. 2-3, pp. 192-200, 2008.

[7] K. Kümmerer, A. Al-Ahmad, and V. Mersch-Sundermann, "Biodegradability of some antibiotics, elimination of the genotoxicity and affection of wastewater bacteria in a simple test," Chemosphere, vol. 40, no. 7, pp. 701-710, 2000.

[8] K. H. Wammer, A. R. Korte, R. A. Lundeen, J. E. Sundberg, K. McNeill, and W. A. Arnold, "Direct photochemistry of three fluoroquinolone antibacterials: norfloxacin, ofloxacin, and enrofloxacin," Water Research, vol. 47, no. 1, pp. 439-448, 2013.

[9] M. M. Huber, S. Canonica, G.-Y. Park, and U. von Gunten, "Oxidation of pharmaceuticals during ozonation and advanced oxidation processes," Environmental Science and Technology, vol. 37, no. 5, pp. 1016-1024, 2003.

[10] J. M. Nelson, T. M. Chiller, J. H. Powers, and F. J. Angulo, "Fluoroquinolone-resistant Campylobacter species and the withdrawal of fluoroquinolones from use in poultry: a public health success story," Clinical Infectious Diseases, vol. 44, no. 7, pp. 977-980, 2007.

[11] V. Rafalsky, I. Andreeva, and E. Rjabkova, "Quinolones for uncomplicated acute cystitis in women," Cochrane Database of Systematic Reviews, vol. 3, Article ID CD003597, 2006.

[12] J. S. Wolfson and D. C. Hooper, "The fluoroquinolones: structures, mechanisms of action and resistance, and spectra of activity in vitro," Antimicrobial Agents and Chemotherapy, vol. 28, no. 4, pp. 581-586, 1985.

[13] K. Eguchi, H. Nagase, M. Ozawa et al., "Evaluation of antimicrobial agents for veterinary use in the ecotoxicity test using microalgae," Chemosphere, vol. 57, no. 11, pp. 1733-1738, 2004.

[14] OECD, Guideline for Testing of Chemicals 203. Fish, Acute Toxicity Test, OECD, Paris, France, 1992.

[15] OECD, Guideline for the Testing of Chemicals 215. Fish, Juvenile Growth Test, OECD, Paris, France, 2000.

[16] V. I. Lushchak, T. V. Bagnyukova, O. V. Lushchak, J. M. Storey, and K. B. Storey, "Hypoxia and recovery perturb free radical processes and antioxidant potential in common carp (Cyprinus carpio) tissues," International Journal of Biochemistry and Cell Biology, vol. 37, no. 6, pp. 1319-1330, 2005.

[17] I. Carlberg and B. Mannervik, "Purification and characterization of the flavoenzyme glutathione reductase from rat liver," The Journal of Biological Chemistry, vol. 250, no. 14, pp. 54755480, 1975.

[18] W. H. Habig, M. J. Pabst, and W. B. Jakoby, "Glutathione S-transferases. The first enzymatic step in mercapturic acid formation," The Journal of Biological Chemistry, vol. 249, no. 22, pp. 7130-7139, 1974.

[19] P. K. Smith, R. I. Krohn, G. T. Hermanson et al., "Measurement of protein using bicinchoninic acid," Analytical Biochemistry, vol. 150, pp. 76-85, 1985.

[20] H. Aebi, "Catalase in vitro," Methods in Enzymology, vol. 105, pp. 121-126, 1984.

[21] X. Nie, J. Gu, J. Lu, W. Pan, and Y. Yang, "Effects of norfloxacin and butylated hydroxyanisole on the freshwater microalga Scenedesmus obliquus," Ecotoxicology, vol. 18, no. 6, pp. 677-684, 2009.

[22] S. Stepanova, E. Praskova, L. Chromcova et al., "The effects of diclofenac on early life stages of common carp (Cyprinus carpio)," Environmental Toxicology and Pharmacology, vol. 35, pp. 454-460, 2013.

[23] D. Zivna, L. Plhalova, E. Praskova et al., "Oxidative stress parameters in fish after subchronic exposure to acetylsalicylic acid," Neuroendocrinology Letters, vol. 34, pp. 116-122, 2013.

[24] Z. H. Li, P. Li, and T. Randak, "Ecotoxicological effects of short-term exposure to a human pharmaceutical Verapamil in juvenile rainbow trout (Oncorhynchus mykiss)," Comparative Biochemistry and Physiology C, vol. 152, pp. 385-391, 2010.

[25] M. Bartoskova, R. Dobsikova, V. Stancova et al., "Evaluation of ibuprofen toxicity for zebrafish (Danio rerio) targeting on selected biomarkers of oxidative stress," Neuroendocrinology Letters, vol. 34, pp. 102-108, 2013.

[26] B. Chance, H. Sies, and A. Boveris, "Hydroperoxide metabolism in mammalian organs," Physiological Reviews, vol. 59, no. 3, pp. 527-605, 1979.

[27] R. T. di Giulio and D. E. Hinton, The Toxicology of Fishes, CRC Press, Taylor and Francis Group, Boca Raton, Fla, USA, 2008.

[28] R. Oliveira, S. McDonough, J. C. Ladewig, A. M. Soares, A. J. Nogueira, and I. Domingues, "Effects of oxytetracycline and amoxicillin on development and biomarkers activities of zebrafish (Danio rerio)," Environmental Toxicology and Pharmacology, vol. 36, pp. 903-912, 2013.

[29] N. Wang, N. Nkejabega, N.-N. Hien et al., "Adverse effects of enrofloxacin when associated with environmental stress in Tra catfish (Pangasianodon hypophthalmus)," Chemosphere, vol. 77, no. 11, pp. 1577-1584, 2009.

[30] E. Hodgson, A Textbook of Modern Toxicology, John Wiley \& Sons, Hoboken, NJ, USA, 2004.

[31] V. I. Lushchak, "Environmentally induced oxidative stress in aquatic animals," Aquatic Toxicology, vol. 101, no. 1, pp. 13-30, 2011.

[32] K. B. Storey, "Oxidative stress: animal adaptations in nature," Brazilian Journal of Medical and Biological Research, vol. 29, no. 12, pp. 1715-1733, 1996.

[33] Z.-H. Li, V. Zlabek, J. Velisek et al., "Acute toxicity of carbamazepine to juvenile rainbow trout (Oncorhynchus mykiss): effects on antioxidant responses, hematological parameters and hepatic EROD," Ecotoxicology and Environmental Safety, vol. 74, no. 3, pp. 319-327, 2011. 

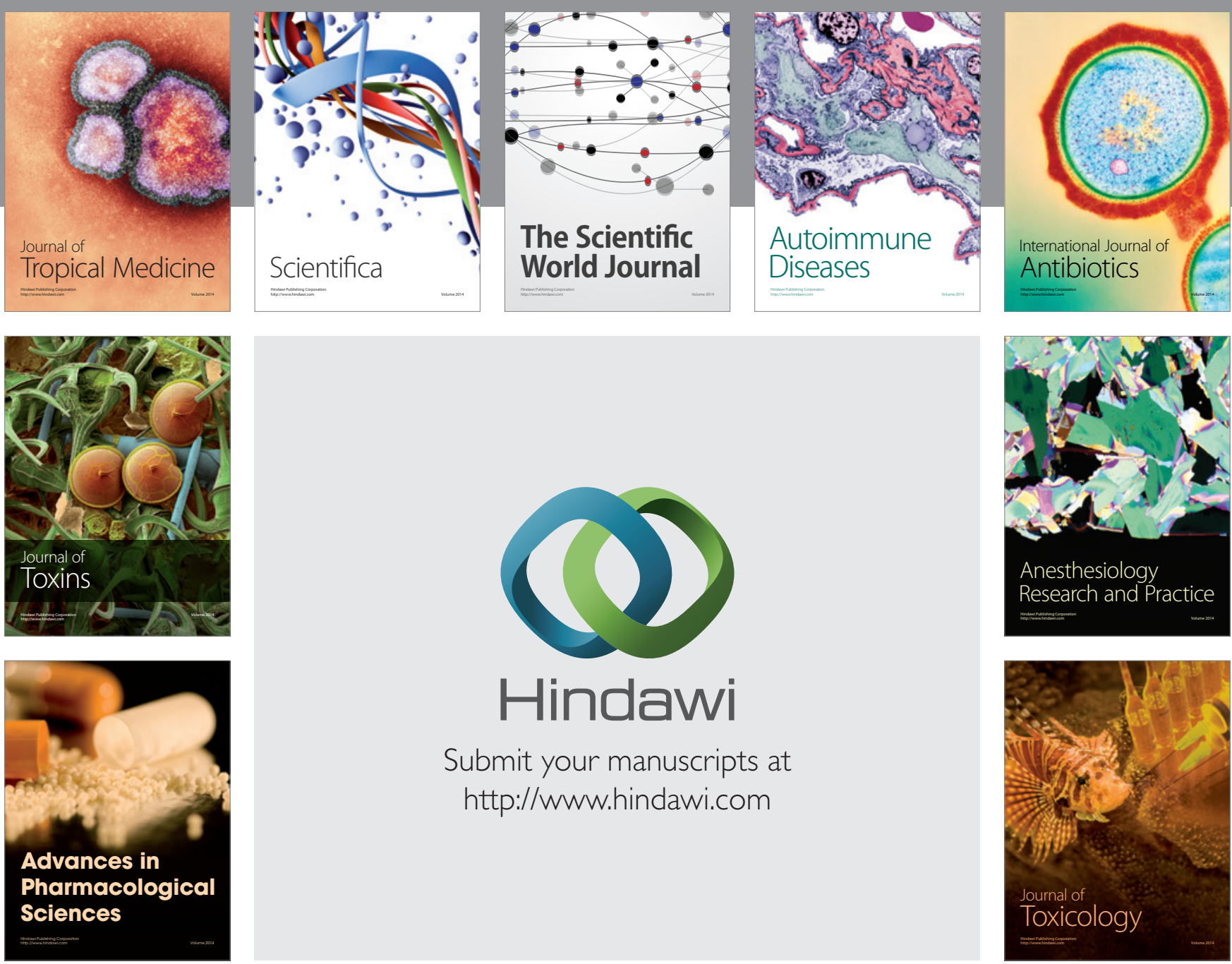

\section{Hindawi}

Submit your manuscripts at

http://www.hindawi.com
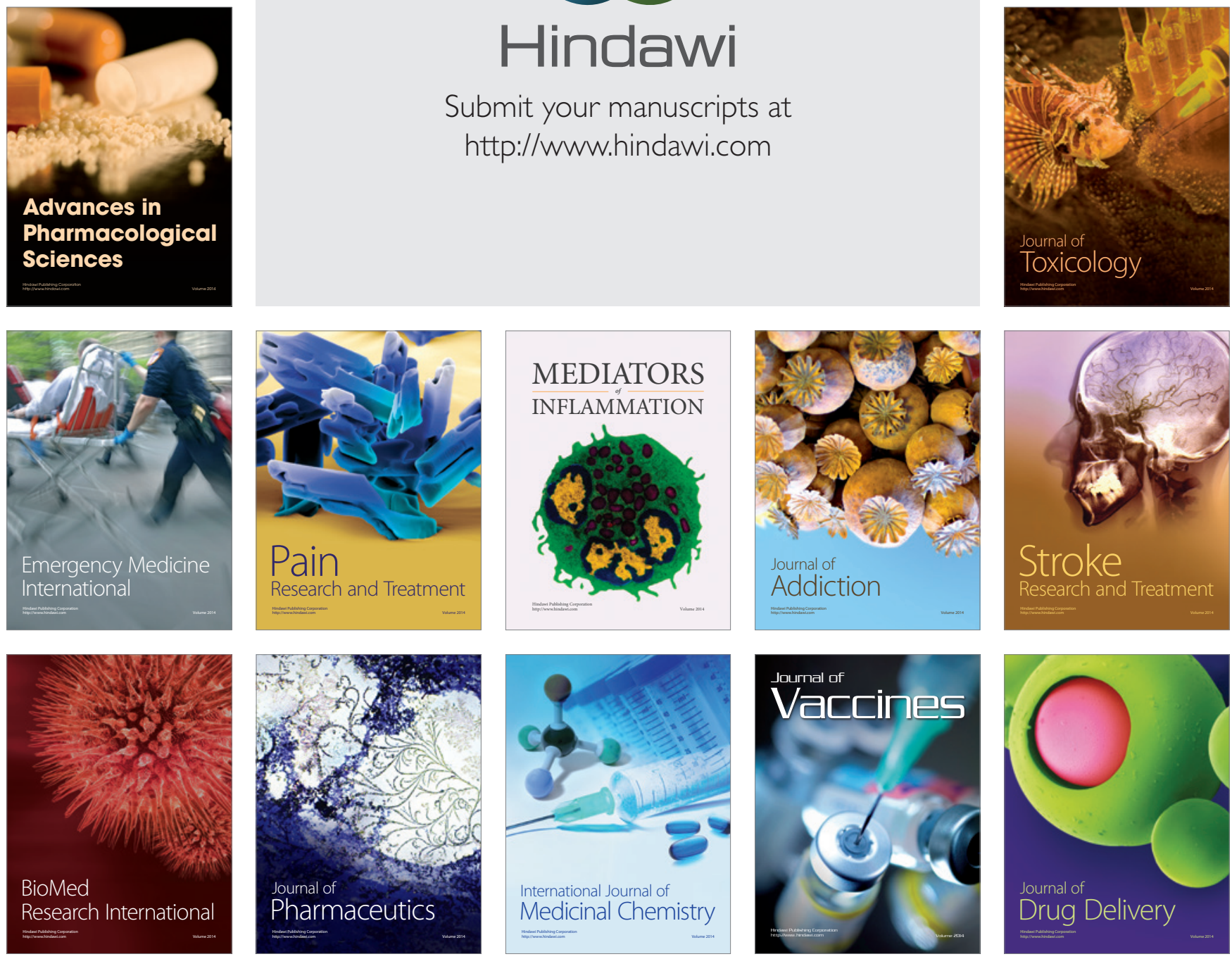